\title{
TURDS, TRAITORS AND TOSSERS: THE ABUSE OF UK MPS VIA TWITTER
}

\section{INTRODUCTION}

The murder of the Jo Cox MP in June 2016 drew attention to the abuse, threats and violence directed towards political representatives in democracies. Though there was no evidence that Cox's killer had directly engaged in online harassment, it highlighted the experiences of abuse towards MPs on social media platforms. Twitter threats, impersonations and trolling became an increasing matter of concern, as a number of MPs highlighted the almost daily barrage of abusive and threatening messages. Besides the obvious threat to MPs themselves, social media sites have been accused of facilitating the coarsening of democratic debate and allowing for the normalization of abuse, particularly against female representatives. At one level, social media abuse could be the latest chapter in a long history of attacks on politicians - some have even suggested that abuse is simply a reflection of political anger and that any attempts to control social media platforms are a means of protecting politicians from the strength of public opinion (O’Neill, 2015). Alternatively, online abuse has been perceived as a symptom of apparently increasing levels of political polarisation in western democracies. The Deputy Speaker of the House of Commons, has argued recently that online abuse undermines democracy by potentially restricting debate on emotive issues for fear of abuse (Home Affairs Select Committee, 2017).

Despite the obvious political concerns and media attention, there has been relatively limited specific research on the phenomenon and few attempts to actively quantify the extent of the problem. ${ }^{1}$ Anecdotal media reporting suggests high and increasing levels of abuse on Twitter, in particular. This research, attempts to provide a benchmark through quantifying the extent, scale and nature of the abuse of MPs via Twitter, as well as exploring some of the causes. Additionally, we have sought to gather evidence on those engaged in abuse - are they the stereotypical spottyyouth loners? Or, are there common patterns, networks and profiles to abusers? To assess these questions, we gathered a dataset of over 270,717 tweets sent directly to the 573 UK MPs with Twitter accounts over a two and half month period (November 2016-January 2017). These were sifted to identify around 7,000 tweets that contained abusive messages or hate speech (see definitions below) which were then further analysed.

\section{MPS, ABUSE AND SOCIAL MEDIA}

Given that social media abuse is a relatively new phenomenon it is perhaps not surprising that there is a relatively limited pool of previous academic research and literature. Despite the lack of literature, contextual information is available through media reports of the abuse of MPs. In analysing the disparate academic literature, four explanatory themes emerge: long-standing concerns with mental illness; the nature of social media technologies and their associated communication styles; politically based explanations which see abuse stimulated by a growth of political polarization or extremism; and, finally, explanations which view abuse in terms of broader social problems around identity.

\section{Psychological explanations: Mental illness}

Whilst there has been increased recent attention on social media abuse of MPs it is worth remembering that politicians have always been on the receiving end of abuse, threats and violence; with reports dating back from over one-hundred years (James et al, 2013). Although the lack of research pre-social media and the more private nature of communications make it somewhat difficult to accurately compare eras. Nevertheless, one long-standing explanation of threats and abuse towards MPs is the connection to mental illness and psychological disorders as

\footnotetext{
${ }^{1}$ A subsequent study of social media abuse directed at candidates, (rather than MPs), in 2017 UK election was conducted by a research team at University Sheffield in collaboration with Buzzfeed. The results of the study were similar in terms of overall levels of abuse and gendered nature of abuse (Buzzfeed, 2017b).
} 
explanations for abuse of public figures generally (James et al, 2007; Dietz and Martell, 1989). Many of these types of studies originate from the psychiatry or social psychology research fields. In the main, they involve self-reporting from MPs and focus on threatening behaviour, physical attacks, and stalking rather than abuse per se. Yet, research going back to the 1980s indicates the prevalence of links between some forms of mental illness and the targeting of politicians. MPs attract abuse due to their increased public profile, along with associated perception as people with power, that attracts members of the public with "idiosyncratic personal causes or quests for justice in a manner that has attracted the term 'fixation". (James et al, 2016:2).

More recent studies in a range of democracies, (UK, US, Canada, Australia, Norway, New Zealand), appear to highlight high levels of abuse and threatening behaviour including physical attacks, stalking, harassment, threats and inappropriate communications and common links to mental disorders amongst abusers (Adams et al, 2009; James et al, 2016; Pathe et al, 2014; Schoeneman-Morris et al, 2007). However, one study, (from New Zealand), notes that whilst MPs are reporting high levels of social media abuse/threats, compared to face-to-face meetings it was more difficult to determine whether mental illness was a factor. Furthermore, MPs tended to believe that abuse via social media was prompted by political disenchantment and less likely to lead to violence (Every-Palmer $e t$ al, 2015). Other research has suggested a more mundane factor in online abuse - boredom and a desire to attract attention afforded by anonymity, rather than a political or serious threat to endanger (Buckels, et al, 2014; Shachaf \& Hara, 2010). This suggests that while online abuse is unpleasant and threats are often made, these are an aspect of online abuse, or trolling, to a well-known figure rather than a necessary indication or threat to injure.

\section{Technological Explanations: Anonymity and Personalisation}

A second area of research focuses on the nature of the technological platforms themselves, especially social media, and resulting changes in communication style. The internet has often been viewed as intensifying, accelerating and even routinising the problem of abuse. This is somewhat ironic given the high, normative, hopes in the e-democracy literature (Barber 1998; Coleman, 1999, Shane 2004). Initially, such technologies were seen as having the potential to foster a more continuous, inclusive, conversational and mutually understanding relationship between the represented and their representatives (Coleman, 1999, 2005; Jackson, 2003; Lilleker and Jackson, 2014; Williamson, 2009). Subsequent empirical research, led to regular criticisms that MPs were failing to use the full potential of interactive technologies, ignoring dialogue and focusing on broadcasting or political marketing thus further distancing themselves from the public (Jackson and Lilleker, 2010; Williamson 2009; Francoli and Ward, 2008).

Social media communication, is impacting on the quality of engagement for a number of reasons: Firstly, the relative low cost of communication, arguably means that it is easier to access representatives than ever before (Shulman, 2009). The downside to this is that because communication is easy and immediate, it can stimulate more emotional and less thought-through engagement (Papacharissi, 2004; Rowe, 2015). Secondly, on some internet platforms, the anonymity provided contributes to what have been referred to as disinhibition effects (Suler, 2004; Joinson, 2007) - where citizens are freed from social cues and constraints to express views publicly in ways that they wouldn't in everyday conversation. The anonymity factor is also seemingly further strengthened by a sense that social media spheres are somehow not subject to same legal restraints as traditional media or face-to-face communication and that perpetrators of abuse are unlikely to face sanction. Thirdly, the nature of communication online, it has been argued, has become more informal and more personalized. At one level, this reflects longer-term shifts in social attitudes towards authority figures that have become less deferential and hierarchical (Norris, 1999). Social media, such as Twitter, with its relative restriction in terms of message length, lends itself towards shorter, punchier forms of communication, arguably bringing with it the risk of more direct and impolite statements. Several studies have noted a growth in the informalisation and personalization of political communication online (Serfaty, 2010) and a blurring of the boundaries between private and public spheres. Politicians are now often advised to seek authenticity in their online personas and to humanize themselves through increasing levels of personalization (Hermans and Vergeer, 2013; Karvonen, 2010). Arguably, 
such strategies and language also invite more personalized (negative) comments in return. For instance, Theocharis et als (2016) study of 2015 EU election candidates in a range of countries found that those engaging in dialogue and interaction tended to generate more negativity in return, although they couldn't determine causality.

\section{Political explanations: the Polarisation of Debate?}

A more politically focused and increasingly popular explanation of social media abuse is the notion of increasing levels of polarization and populism amongst electorates in many western democracies. This links abuse and threats to a more extreme and divided climate of political debate, which, whilst not new, has been accelerated by the information and communication environment online (Prior, 2013; Leikes et al, 2015; Colleoni et al 2015). The internet's role in polarization has been disputed (Barbara, 2015) but its apparent facilitation of divided and abusive communication sphere rests on a number of factors: Firstly, the internet has been seen as increasing the number of partisan sources in circulation which are not subject to the same professional journalistic standards as traditional media. Secondly, voters increasingly consume such partisan content based on selective exposure i.e. they are drawn to material that backs up pre-existing beliefs or interests (Prior 2007). Thirdly, selective exposure is then interlinked with, people's online networks and filters. In part, this reflects automated filter bubbles which select or organize what we see online based on previous browsing history. Additionally, the argument behind polarization suggests that our online networks are largely homogenous, with like-minded people communicating with one another (McPherson et al, 2001; Sunstein, 2009). Hence, Twitter, is often seen as an echo-chamber where people of similar political outlooks spread or replicate each other's messages but are rarely challenged by alternatives viewpoints. The suggested longerterm impact of increased exposure to like-minded views is the adoption of more extreme positions (Mutz and Martin, 2001). This filtering is then heightened by the aforementioned anonymity reducing social and psychological inhibitions and thus stimulating some individuals to express more extreme views and indulge in abuse of opponents (Joinson, 2007).

In the UK, mainstream media has linked upsurges in general levels of abuse against MPs to the increasingly divided and oppositional nature of politics heightened by several recent and ongoing debates. The binary (yes/no) nature of two recent referenda in the UK (the 2014 Scottish Independence and the 2016 EU referenda) have been viewed as significantly heightening the polarized nature of UK political debate. In the wake of the Brexit vote, there were many highprofile accounts of direct threats and hate speech mainly over social media. For example, David Lammy, (Labour MP, Tottenham), reported a welter of racist abuse on social media to the Police following his call to block Brexit (Guardian, 4 July 2016). Anna Soubry MP a leading Conservative remain supporter also reported death threats (Independent, 2 December, 2016). From the leave perspective, Rebecca Harris (Conservative MP, Castle Point,) has claimed in relation to online abuse:

Another shocking thing in the wake of Brexit is that nice, normally liberal-minded peoplepeople who would profess to be progressives - also think it is reasonable to abuse 17 million of their fellow countrymen.... They turn into keyboard warriors and say things that they would never dream of saying face to face to an individual (Hansard, 7 July 2016).

Whilst polarization is often seen as heightening partisan divisions, intra party divisions can also generate highly polarized debates. In the UK, the arguments within the Labour Party between supporters of Jeremy Corbyn and his opponents within the Parliamentary Labour Party (PLP) led to continual claims of abuse from both sides. The parliamentary vote of bombing of Syria (December 2015) sparked several reports of offensive messages including death threats to 25 Labour MPs who supported bombing (in opposition to Corbyn's position). Challenges to Corbyn's leadership also seemed to have provoked significant abuse. For example, MP Angela Eagle's Facebook tribute to Jo Cox was targeted by apparently Corbyn-supporting trolls whilst Corbyn opponent Tom Blenkinsopp MP reported one abuser to the police who was subsequently revealed to be a fellow party member (Gazette, 1 July 2016). 
Identity factors: gender and race

The more technological determinist explanations of online abuse might lead us to expect generalized and randomised abuse towards MPs. Yet, both anecdotal and research-led reports indicate that certain types of MPs are targeted for social media abuse. Moreover, this is not simply just a question of the volume of abuse but also the nature of that abuse. In particular, media coverage has focused on abuse and threats directed at female representatives, (especially, younger women MPs), and those from ethnic minorities. Recent evidence given to the Home Affairs Select Committee indicated that Muslim and Jewish women were indeed the prime targets of abuse (Home Affairs, Select Committee, 2017).

Female MPs themselves have repeatedly reported widespread and alarming levels of threats of sexual violence and repeated harassment, as well as more general misogynistic comments. In the UK, two men have been jailed for online threats made against MPs (Stella Creasy, 2014 and Luciana Berger, 2016), whilst Jess Phillips MP revealed that she had received over 600 rape threats in one evening via Twitter (Daily Telegraph, 31 May 2016). A recent BBC Radio 5 survey of female MPs (from all parties) indicated that the overwhelming majority (nine out of ten) reported receiving online and verbal abuse from the public whilst a third had considered quitting as a result (BBC News, 25 January 2017).

Interestingly, and perhaps revealingly, this does not seem to be simply a UK problem. The InterParliamentary Union research identified global issues of abuse and harassment suffered by female representatives in wide range of countries and political systems. The research further noted that the general abuse of female representatives tended to be heightened by three factors: age; ethnicity and length of service. Younger representatives of minority ethnic backgrounds suffered more abuse especially when first elected (IPU, 2016). Media reports from Canada, Ireland and Italy in the past year all indicate similar patterns of threats and abuse via social media platforms (CBC News, 2016, 2017; the Journal.ie, 2016; BuzzFeed News, 2017a).

In part, the abuse of female politicians has been linked to the high level of misogyny online (Demos, 2014, 2016). Arguably, this is then exacerbated in political context where research suggests that political online discussion, in a range of countries, has consistently shown to be dominated by men (Stromer-Galley, 2002; Harp and Tremayne, 2006; Trammell and Keshelashvili, 2005; Albrecht, 2006; Jensen, 2003). Some studies have argued, that directed threats against women MPs relate to attempts to delegitimise female politicians, restrict their rights to communicate and inhibit them from taking active part in the political arena but also sense that abusers feel threatened by high profile woman politicians speaking out (IPU, 2016).

All these approaches have pointed towards a significant increase in the abuse of MPs with social media being a key driver. Although overall abuse is a considered to have grown, certain types of threatening and violent messages are also seen as becoming particularly prevalent and targeted at certain demographic groups of MPs. Yet, whilst this may be the case, reviewing existing studies highlights several related remaining problems. Firstly, there is a limited amount of consistent and precise empirical evidence. Secondly, comparing longitudinally over time between pre-internet and internet eras remains problematic, as prior to the emergence of social media platforms much of the communication between representatives and represented was essentially private. Thirdly, methodologically, there are issues both around definitions of abuse and the fact that recent studies tend to rely on self-reporting by MPs that are potentially fraught with inconsistency. Finally, there is also a need for theory-building around catalysts and drivers for social media abuse.

\section{RESEARCH QUESTIONS}

In light of the above discussion, the main objective of our study was to provide some quantifiable evidence of abuse on Twitter and provide a benchmark for future empirical studies. Therefore, we sought to answer a number of broad questions: 
- What is scale and extent of direct abuse of MPs via Twitter? Whilst the assumption is that abuse via social media is widespread and growing - there is very little quantitative evidence. James et als (2016) UK study, using 2010 data, indicated 10\% of MPs reporting abuse via social media but this was at a relatively early stage of social media development. Consequently, we wanted to quantify both the overall level of abuse (volume) the spread amongst MPs i.e. how many MPs received abusive tweets.

- Are there particular patterns and targets amongst MPs for abuse? In line with expectations that some individuals and groups of MPs are targeted more than others, we sought to identify: (a) which individual MPs were targeted; (b) whether particular groups of MPs were targeted (either by party, gender or ethnicity). Given the level of reported abuse aimed at women representatives - we were particularly interested to see whether our data confirmed this.

- What types of abuse are prevalent and are certain types of abuse directed at particular MPs? While there is standard definitions for hate speech and identifying threatening communication is arguably easier, we were interested in whether we could effectively categorise abuse. Additionally, we wanted to how far abuse could be linked to distinct political debates (such as Brexit) and whether particular groups of MPs received more threatening types of communication.

- Are there any patterns or profiles of twitter-politician abusers? The stereotypes of internet trolls/abusers is of social inadequate young males with addictions to technology. We sought to find out whether there were serial abusers of politicians generally, whether there were networks of Twitter abusers and again whether there is any political or demographic dimensions to this.

\section{DATA \& METHODS}

To answer our research questions there were several methodological hurdles: definitional issues around what constitutes abuse; how to apply such definitions in a social media environment; how to detect abuse; and how to determine the boundaries of MP abuse.

\section{Defining Abusive Tweets and Hate-speech}

There is considerable and complex debates surrounding the definitions of abuse and hate-speech. Each definition has at least some level of subjectivity alongside a mix of cultural factors. Previous approaches to defining abuse and hate-speech have used purposely-broad definitions. Burnap and Williams (2013), for example, allowed their human coders to self-define what hate-speech was. Alternatively, other researchers allow victims to define what they would consider abusive (Farris et al, 2016). However, the methodological approach here, required a much more robust understanding before the data set could be coded.

\section{Definition of Abuse}

Definitions of harassment or abuse generally cover a wide range of content that has the intention to disturb or insult an intended person. However, there are two ontological approaches that divide most definitions. The first have their foundations either in defining abuse as an action/intention, or as an impact on a victim. For example, Lenhart et als (2016) definition is that harassment is "unwanted contact that is used to create an intimidating, annoying, frightening, or even hostile environment for the victim" [emphasis added]. The focus here is on abuse/harassment being felt by the victim and not the action itself. The second set of definitions base their conception of abuse on the act of abuse, whereby the action, or intention, of the message itself is the basis for abuse. This can be seen in Bartlett et al (2014) whereby messages on Twitter were 
used to find abuse, and, therefore, could not test if victims felt abused. This highlights the issue with victim-based definitions in research; in each case of abuse, one must know that the victim feels abused or harassed. In comparison, action-based definitions can be taken from the message itself, if the context is also considered.

Computer science approaches provide a further method for defining abuse. Definitions from this discipline, rely on libraries of words which can be used to identify abusive content instead of traditional definitions. ${ }^{2}$ However, this has its own issues that make it unsuitable for this type of research. Applying a keyword-based methodology to Twitter messages has proven highly unreliable (Nobata et al, 2016: 146). Furthermore, libraries of words do not in themselves provide context like the issues with sentiment analysis (discussed below). So, while the computer science approach might be useful in identifying negative messages, machine algorithms cannot automatically detect, with a high degree of accuracy, the complex and subjective nature of abuse.

For the reasons, above, we used Bartlett et al's definition of abuse on Twitter, where abuse is defined as messages directed at a specific person with the intent to cause harm or distress. This can include casual use of slurs of derogatory stereotypes, so long as it is a specific and is personal attack at "you". (2014:24). This definition while open to some interpretation, allows itself to be coded directly into the dataset. Thus, tweets which are found to contain offensive or profane words directed to an MP can be argued to be abusive (see Table 1).

\section{Definition of Hate-speech}

Hate speech can be defined as an expression of hatred towards a group, based on protected characteristics (such as ethic background, religious identity, sexuality, or gender) especially so towards groups who do, or have, faced structural and societal disadvantage (Ferris et al, 2016:5). However, as with all definitions concerned with a subjective area, there has been a significant debate about what can be considered hate-speech.

Sellers (2016:25-30) conducted a comprehensive review of the definitions of hate-speech across common vernacular, academic, and legal. It was found that most definitions of hate-speech contain eight common themes:

1) Insults or undesirable communication to a specific or easily identifiable group

2) Content that expresses hatred towards groups

3) Speech that causes harm

4) When the speaker intends harm or bad activity

5) The speech incites bad actions beyond the speech itself

6) The speech is either public or directed at a member of the public

7) The context makes violent response possible

8) The speech has no redeeming purpose

What is clear from this framework is that while most forms of hate-speech can be considered harassment or abuse; not all abuse is hate-speech. Furthermore, it gives a working framework for deciphering what is hate-speech without the input of this papers authors, mitigating our own personal subjectivity while managing a definition.

Using these definitions, we created a classification system for the identification of abuse on Twitter towards MPs. This simple classification put tweets towards MPs into one of four categories: Non-abusive, Not-directed, Abusive, or Hate-speech (See Table 1).

\footnotetext{
${ }^{2}$ See also Luis Von Ahn's list of offensive/profane words: https://www.cs.cmu.edu/ biglou/resources/
} 


\begin{tabular}{|c|c|c|}
\hline Classification & Reasoning & Examples \\
\hline Non-abusive & $\begin{array}{l}\text { Tweet contains no profanity or } \\
\text { derogatory language }\end{array}$ & $\begin{array}{l}\text { - } @<\text { MPsHandle }>\text { Can you tell me how you intend to } \\
\text { vote in tonight's debate } \\
\text { - } \quad \text { I hope I get to see } @<\text { MPsHandle }>\text { tonight! }\end{array}$ \\
\hline Not-directed & $\begin{array}{l}\text { Tweet contains abusive slurs or } \\
\text { hate-speech, but not directed } \\
\text { towards the MP }\end{array}$ & $\begin{array}{l}\text { - Fucking Pot holes again. @ }<\text { MPsHandle }>\text { Sort it } \\
\text { out. } \\
\text { - That group are a bunch of whores. I hope } \\
@<\text { MPsHandle }>\text { kicks them out. }\end{array}$ \\
\hline Abusive & $\begin{array}{l}\text { Abusive, profane language } \\
\text { directed towards an MP }\end{array}$ & $\begin{array}{l}\text { - } @<\text { MPsHandle }>\text { You're a Wanker } \\
\text { - I hope that } @<\text { MPsHandle }>\text { knows he's a complete } \\
\text { fucker. }\end{array}$ \\
\hline Hate-speech & $\begin{array}{l}\text { Profane or derogatory language } \\
\text { which relates to a characteristic } \\
\text { the MP belongs; language which } \\
\text { implicitly or explicitly implies or } \\
\text { encourages threats towards an } \\
\text { MP }\end{array}$ & $\begin{array}{l}\text { - } @<\text { MPsHandle }>\text { is a stupid kike. } \\
\text { - Well that proves how much of a slut } @<\text { MPsH } \\
\text { andle }>\text { is. } \\
\text { - I hope } @<\text { MPsHandle }>\text { gets what's coming to him: } \\
\text { A baseball bat. }\end{array}$ \\
\hline
\end{tabular}

\section{Data Collection}

The findings of this paper were generated by a dataset of 270,717 tweets collected from November 14, 2016 to January 28 ${ }^{\text {th }}, 2017$ to MPs by Twitter users. The actual number of Tweets collected in the database was more than this, but were filtered out to exclude spam, empty or repeated tweets. For the data collection, we utilized the Twitter collection software $T A G s^{3}$. This tool automates the data collection process by routinely accessing Twitter's search API with a query and returning with tweets that fit the search parameters inputted alongside associated meta-data. A potential challenge with this method is that while Twitter does have tools to deal with abusive messages, details about its implementation are a closely guarded secret (Ho, 2017). Therefore, it is possible that Twitter may have removed abusive tweets before they were collected. However, as displayed below, the level of abusive messages collected is ample for analysis.

The identification of tweets sent to MPs was simplified by the structure of Twitter. Users of the social media platform often self-code tweets through either hashtags, or, by directing their posts to specific intended audiences. In the case of hashtags, users can precede a word, category, or phrase by a hash symbol (\#<word $>$ ) to denote that the tweet is on a particular subject, or give the tweet an envisioned purpose. To specify an immediate audience, users can include the mention function (@<recipient handle $>)$ that can take the form of direct messages to the recipient, replies to a recipient's tweet, or simply mentioning them in a standard tweet. Alternatively, users can choose not to code the messages if their intended immediate audience is to be limited to others who follow them directly. For this research, the self-coding of tweets avoids some of the methodological issues present in social media research (Murthy, 2017). It can be assumed if a user is directing or notifying another they are trying to communicate with them, and this can be distinguished from all other tweets through the following search term:

To:@ $<$ MPsTwitterHandle1> OR @ $<$ MPsTwitterHandle2> OR @ $<$ MPsTwitterHandle $3>\ldots$

\footnotetext{
${ }^{3}$ TAGS (or Twitter Archive Google Sheets) and is available at https://tags.hawksey.info/
} 
This search term was expanded to include all MPs Twitter handles and then imported to TAGs for data collection. The MPs' Twitter handles used in the search were taken from a pre-collected database of all verified Twitter accounts which included an MP's Twitter handle, age, gender, party affiliation, constituency, and account details which included age of the account, activity, and biographic information. This database of MPs account handles $(n=573)$ was updated on a weekly basis to check for MPs who had left or joined the service throughout the data collection period.

\section{Detecting Abusive Tweets and Hate-speech}

Using the definition of abuse described above, we created a semi-automated process for the identification of abusive tweets and those that contained hate-speech. Fully automated classification systems have been used to classify tweets through methods such as sentiment analysis, distant supervision, or machine learning (Ratkiewicz et al, 2011; Chen, 2012; Burnap \& Williams, 2013). These auto-classifiers still present wide margins of error and despite becoming more accurate they are far from perfect. Human coding of the entire dataset would be a preferable alternative but there are issues of resource, human error, and subjectivity (Sloane, 2017:168). An optimal method would be to use human intelligence tasks (HITs) to code the data, however, this does come with significant resource requirements (Buhrmester et al, 2011; Sloane et al, 2015). Consequently, a multi-layered approach was taken which used sentiment analysis, keyword identification, and manual verification to identify abusive and hateful tweets within the dataset.

Firstly, sentiment analysis (SentiStrength) was applied to the dataset (Thelwall et al, 2012). This software uses a lexical approach to detect both positive and negative sentiment strength. Each tweet was ranked from most negative sentiment to least negative sentiment using two scores. These two scores were taken from the SentiStrength analysis: a positive sentiment score, a figure is given from 1 (no positive sentiment) to 5 (very strong positive sentiment); and for negative sentiment a figure is given from -1 (no negative sentiment) to -5 (very strong negative sentiment). Sentiment analysis systems are good at understanding the overall sentiment of a tweet, however, the system cannot detect the direction of the sentiment. For example, a tweet to an MP may be insulting, triggering a high negative sentiment, but the analysis tool cannot detect if this negativity is directed towards the MP. The system was useful for ranking all the tweets by overall sentiment, which significantly increased the speed of the second stage of analysis.

The second step was to code the top 3,000 negative tweets manually. The definition classifications of abuse and hate speech mentioned above was used to detect if the tweet was abusive or hateful, and then defined if this tweet was directed towards the MP. These codes were then analysed through a summative content and thematic analysis; which identified, and reported patterns of use of particular keywords (Braun \& Clarke, 2006). A total of 78 abusive or hateful keywords were extracted.

The third step was to filter the dataset for tweets that contained any one of the identified keywords. Each tweet was then manually verified to determine if the tweet was abusive or could be considered hate-speech. If tested positive for abuse, we then verified if the MP was the intended recipient of the abuse or hate speech.

\section{Limitations}

There are several limitations to this type of social media research. Firstly, there are limitations on the of Twitter's public search API. The data accessible through this API has restrictions on the number of calls and a cap on the amount of data at any given time (Voss et al, 2017: 244). This was mitigated using TAGs where the collection of tweets was scheduled to avoid the limits set by the Twitter API. 
Secondly, it is expected that the data collection and detection methodologies will underreport on the levels of tweets that contain abuse and hate-speech. Twitter has recognised that the service does enable a significant amount of abuse and hate speech, and have taken some action to reduce the amount on their platform. The exact method of how Twitter detects and removes these tweets, either through user reports or automated methods is a secret, to reduce the ability of abusers to develop a work-a-round. This could mean that some abusive messages sent to MPs may have been deleted before our collection methods could add them to our dataset. Additionally, our method for detecting abusive messages focuses on the detection of abuse and hate-speech using keywords with a high frequency of abuse and hate-speech. This could allow some abusive terms that are less prevalent to be excluded. In addition to this, users may intentionally obscure offensive words (Nobata et al, 2016:146). For example, replacing some letters with non-alphanumeric characters such as the use of dollar signs instead of an 's'. The dataset was developed with the assumption that it marginally underreports abuse and hatespeech.

A third limitation of the research method is the reliance on textual communications, as most messages on Twitter are textual. However, previous research has indicated that a large amount of communication is through both image and video mediums (Laird, 2012).

Finally, political events inevitably lead to individual MPs receiving more hate-speech than they would otherwise attract. For example, Phillip Davies MP, Anna Soubry MP, and Tim Farron MP received a significant amount of online communication over specific events or actions. It is also worth considering that the data collection period included festive holidays, which may have resulted in lower levels of abuse or hate speech towards MPs.

\section{FINDINGS}

\section{Overall Scale of Abuse}

The first area of enquiry within this research was to detect the overall scale of abuse towards MPs on Twitter. Notable journalistic claims have been made surrounding the nature of abuse to MPs online. So far there has not been any clear indication of the overall levels of abuse/hate speech through the Twitter service or online abuse in general (Buckels, et al, 2014: 97). From the total coded dataset of tweets to MPs $(\mathrm{N}=270,717)$ it was found that the proportion tweets which were classified as 'abusive' made up $2.57 \%$ of the dataset $(n=6,952)$. In other terms, twenty-five messages in every thousand tweets contain some type of direct abuse towards an MP.

Despite overall levels of abuse, it was expected that individual MPs would attract different levels of abuse. This is reflected in the dataset. The average MP received 17.99 abusive messages, with a standard deviation of 48.9, and a range of 0 to 677 abusive messages. This suggests that the level of abuse is dependent on other factors than simply being an MP.

In total, $62 \%$ of the MPs had at least one abusive tweet sent to them during the two months $(\mathrm{N}=569 ; n=370)$. This is significantly more than the $10.1 \%$ of MPs who had reported receiving 'inappropriate social media contact' in James et als 2010 survey of UK MPs (2016:10). This is an indication of one of three options: levels of abuse on social media has increased; abuse has remained consistent for each MP but more MPs are now on the service to be abused; or simply that each MPs perception of abuse is different and was therefore under-reported in 2010. However, in reference to the James et al survey of MPs, the number of MPs abused on Twitter is more similar to the amount of abuse received by MPs by letters, fax, or emails with $63.9 \%$ of MPs reporting abuse/harassment through these mediums (2016:10). This implies, that while the scale of abuse may be different, the number of MPs being abused remains comparable to other predominantly textual mediums.

Posts which included hate speech towards MPs occurred at a significantly reduced frequency to 
those categorised as abusive. Only $0.42 \%$ of tweets contained some type of hate speech $(n=125)$ out of the total. Furthermore, the scope of MPs sent tweets containing hate-speech was considerably lower; with $6.6 \%$ of MPs receiving some form of hate speech $(n=38)$. The only comparable research is from Ethiopia which found that $0.7 \%$ of all online political communication contained hate-speech (Gagliardone et al, 2016). In this research, evidence from Ethiopia, anecdotal evidence, and news presence suggested that political hate-speech is more widespread than what this data suggests.

The timeline of when the abusive tweets occurred indicates that abuse was not consistent across the data collection period. Indeed, there is evidence of significant groupings of abuse on particular days. Most notably, there was a significant spike of abuse on December $7^{\text {th }}$. It can be considered that abuse is not a day-to-day occurrence, but instead fuelled by outside factors, political events, or current affairs stories. December $7^{\text {th }}$, for example, was the day that the House of Commons voted on the Government's Brexit timetable. Common user traits of social media are visible, for example, less abuse on the weekends aligns with when people use Twitter. However, there are significant deviations that indicate that abuse is reactive to outside factors.

FIGURE 1: Abusive Tweets by Date

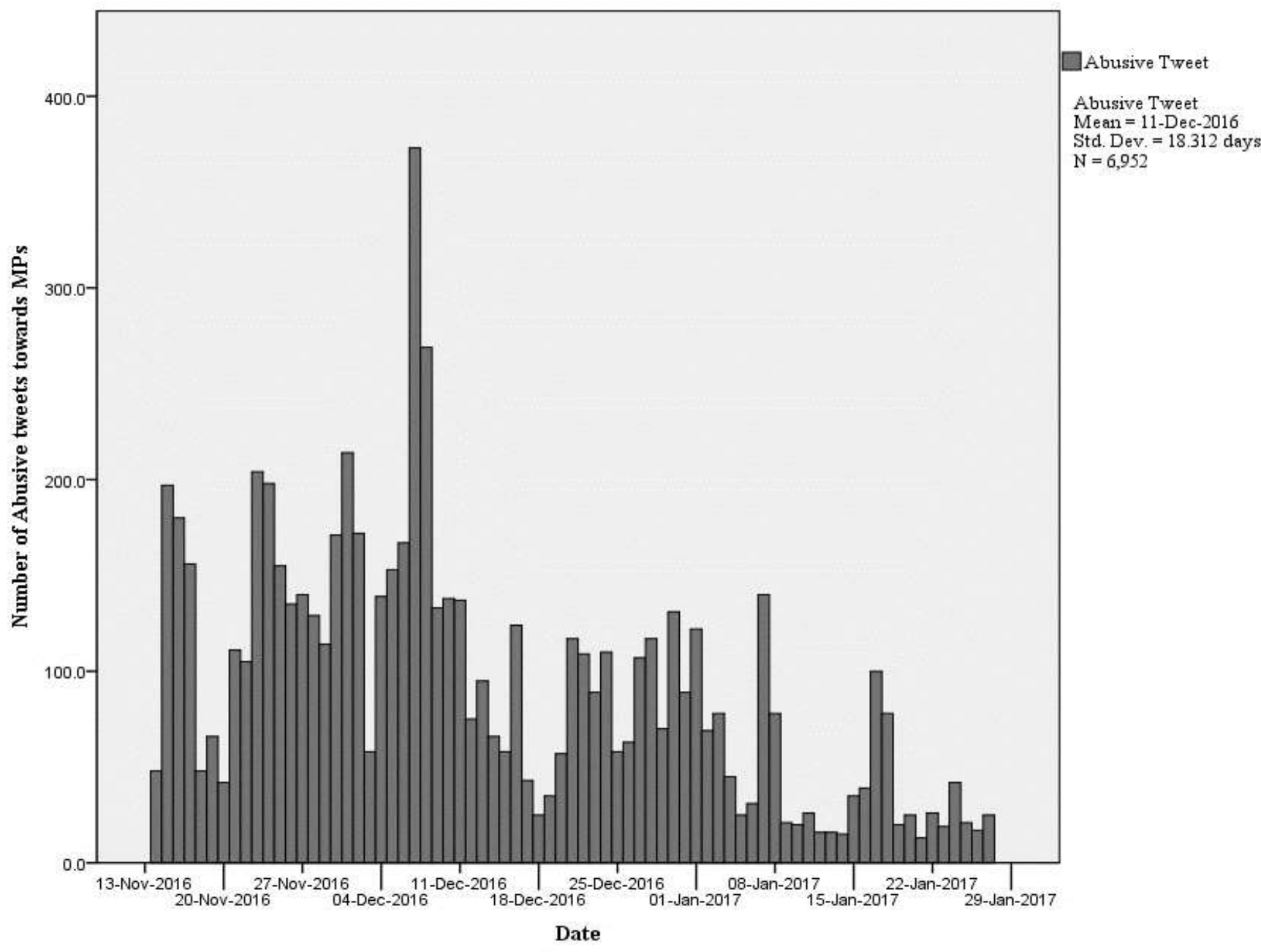


Overall, the evidence suggests that most MPs encounter abuse to some extent on Twitter with the level of abuse differing substantially from one MP to another. Therefore, we tested the levels of abuse across three characteristics: recognition (measured by total tweets received), gender, and political party. The characteristics were tested with the overall dataset, and then again with an interquartile dataset to test the 'average' experience of MPs by treating the experience of the top and bottom twenty-five per cent of MPs in terms of recognition as outliers. This provided a different perspective of abuse towards MPs.

TABLE 2: MPS WITH MORE THAN FIFTY ABUSIVE TWEETS

\begin{tabular}{lccc}
\hline MPs Handle & $\begin{array}{c}\text { No. } \\
\text { Abusive } \\
\text { Tweets }\end{array}$ & $\begin{array}{c}\text { Total No. } \\
\text { Tweets }\end{array}$ & $\begin{array}{c}\text { \% of } \\
\text { Tweets } \\
\text { Abusive }\end{array}$ \\
\hline Jeremycorbyn & 677 & 16,944 & 4.00 \\
Timfarron & 438 & 5,133 & 8.53 \\
BorisJohnson & 409 & 9,452 & 4.33 \\
Michaelgove & 329 & 4,234 & 7.77 \\
theresa_may & 273 & 11,779 & 2.32 \\
Anna_Soubry & 264 & 7,582 & 3.48 \\
ChukaUmunna & 243 & 7,355 & 3.30 \\
nick_clegg & 223 & 3,157 & 7.06 \\
George_Osborne & 198 & 1,505 & 13.16 \\
Jeremy_Hunt & 180 & 2,618 & 6.88 \\
Ed_Miliband & 161 & 2,376 & 6.78 \\
PhilipDaviesMP & 126 & 966 & 13.04 \\
BenPBradshaw & 120 & 1,500 & 8.00 \\
AlexSalmond & 114 & 2,521 & 4.52 \\
HackneyAbbott & 110 & 2,688 & 4.09 \\
DavidTCDavies & 109 & 1,561 & 6.98 \\
OwenSmith_MP & 104 & 2,005 & 5.19 \\
DavidLammy & 101 & 3,507 & 2.88 \\
RhonddaBryant & 78 & 3,521 & 2.22 \\
DouglasCarswell & 75 & 2,559 & 2.93 \\
SarahChampionMP & 72 & 2,388 & 3.02 \\
Jessphillips & 72 & 4,164 & 1.73 \\
RichardBurgon & 71 & 3,816 & 1.86 \\
Andyburnhammp & 57 & 2,933 & 1.94 \\
Labourlewis & 55 & 3,589 & 1.53 \\
PHammondMP & 51 & 2,592 & 1.97 \\
PeteWishart & 51 & 4,353 & 1.17 \\
\hline Total & 4,761 & 116,798 & 4.07 \\
\hline \hline
\end{tabular}

\section{Relationship between recognition against abuse (Overall)}

Measuring the recognition and popularity of an MP in the public eye is fraught with difficulty due to the subjective nature of the terms. However, there are some statistics provided by this database which can be used to determine a value for an MPs individual name recognition and popularity. Cha et al (2010) found that the number of followers a user has does not necessarily relate to the user's name recognition but does to their overall popularity. There was a relationship between mentions and name recognition. Retweets symbolised interest in the content of the tweet rather than the poster. Therefore, by using the measures of followers (for popularity of MP) and @mentions (for recognition) we could measure the impact of these two fields on abuse with linear regression.

The first finding was that increased name recognition has a positive relationship with levels of abuse $(\mathrm{r}=0.893 \mathrm{r} 2=0.797 \mathrm{p}=<0.01)$. This indicates that the more an MP is mentioned on Twitter, the more abuse they receive. 
The second finding is that popularity has a positive relationship with abuse, however, this relationship is weaker than with name recognition $(r=0774 . r 2=0.599 p=<0.01)$. On the assumption that a more popular MP will be liked more, and therefore abused less, this finding should not be surprising (Chen et al, 2010).

\section{Impact of Gender on levels of abuse received}

Gender has some impact on the level of abuse received by MPs. However, despite media reporting of the targeting of female MPs on the service, the data shows that male MPs attract more abuse. Male MPs had three per cent of all tweets sent to them being deemed abusive. This is in comparison to the 1.7 per cent to female MPs. Alternatively, male MPs receive 30 abusive messages in every thousand, compared to the 17 in every thousand received by females. This result was tested with a Point Biserial correlation, which found a positive relationship between being a male MP and receiving abuse $(r=0.39 \mathrm{p}=<.01)$. However, the $\mathrm{R}^{2}(0.02)$ suggests this relationship is only accounts for two per cent of the variation of abusive tweets. Therefore, suggesting while there is a relationship between being a male MP and the levels of abuse on Twitter, this relationship is not as significant as other factors. However, female MPs received significantly higher proportion of hate speech compared to male MPs. Out of all tweets that contained hate speech, $86 \%$ was directed at females. $(\mathrm{N}=125, n=108)$. This result is partly due to our classification where offensive gendered slurs counted as hate-speech, but also due to the increased levels of hate-speech attracted by women. This result does suggest that while women may not receive more unwanted contact than male MPs, the abuse women receive is gendered in its content.

\section{Impact of political party on the levels of abuse received}

The initial analysis of abuse towards MPs segmented by political party suggests that being a member of a national party with a large vote share in the 2015 General Election attracted a larger amount of abuse as a percentage compared to that of parties based in devolved nations of the UK with smaller overall vote shares. This aligns with the findings of the popularity section which suggests the most recognised MPs will attract more abuse and these MPs will belong to the more recognised political parties. Table 2 displays this relationship. It is worth noting that the Liberal Democrats and UKIP are heavily skewed due to individual members. High levels of abuse targeted at the Liberal Democats was mostly accounted for by high levels of abuse directed to its Leader, (at time of study), Tim Farron MP, similarly UKIP's abuse was due to Douglas Carswell, the party's only MP.

\section{The interquartile dataset}

During the analysis, it became clear that the overall dataset was affected by high profile MPs, or by MPs who had an extremely minimal use of the service. Therefore, to test the average MPs experience, we further filtered the data to the interquartile in terms of overall recognition. This filtered database contained $284 \mathrm{MPs}$.

The differences found between the overall and the interquartile show a difference in experience between the most popular and average MPs. Firstly, the interquartile MPs are abused significantly less. Only $0.95 \%$ of tweets to the interquartile contained any abuse, compared to $2.57 \%$ of the overall dataset. There were only two messages considered hate-speech in the interquartile dataset which did not allow for analysis in this area other than to suggest than to confirm that recognition is related to hate-speech $(n=2 ; \mathrm{N}=51,132)$.

The interquartile set showed no difference in terms of the gender relationship with abuse. As with the overall data, male MPs continued to attract a significant amount of abuse, 1.04\% of all tweets abusive for male MPs, compared to $0.7 \%$ of all tweets to female MPs. 


\section{Perpetrators of Abuse}

While there is much to be said about the abuse itself, an overview of the perpetrators of abuse is harder to quantify. Cultural stereotypes of online trolls depict most online abusers as young white males who abuse to alleviate boredom (Hardaker, 2013; Fichman \& Sanfilppo, 2016: 143). However, the quantification and description of online trolls is masked on Twitter, in part due to the optional anonymity, but also because the service does not collect gender or age information from users directly. For these reasons, research into who trolls is problematic. Thus, while some user traits can be analysed from the data, other key identifiers could not be found from this research.

In addition to perceptions of online abusers being young white males, there is also the belief that perpetrators are often nocturnal. For example, Lindsay Hoyle MP called the abusers of MPs keyboard warriors who are active at the middle of the night (Home Affairs Select Committee, 2017). The cultural perceptions created an obvious test: to measure if the abuse of MPs is nocturnal in nature. Using our data, we tested if there were any patterns of abuse in terms of time of day. It was found that the difference between when abusers attacked MPs and overall tweets to MPs was negligible; with the mean abuse occurring at 2:59pm (Std. Dev. $=0.249$ days) compared to the overall mean of $2: 37 \mathrm{pm}$. (Std. Dev. $=0.286$ days). This goes some way to dispel the myth that all online abusers of MPs are surfing the web late at night, or that the time of day can be used to predict when abuse will happen.

One finding is that the perpetrators of abuse towards MPs may do so as a reaction to content by MPs within their social awareness streams. In our dataset, tweets were coded to determine if a tweet was made directly to the MP, or as a reply to tweet an MP had made. In a test, we found a

positive relationship between abuse and the tweet being in the form of a reply $(r=0.22 \mathrm{p}=<0.1)$. This counters the notion that perpetrators purposefully go online to abuse, but instead suggests that the phenomenon of abuse is more often an immediate reaction triggered by what an abuser sees.

TABLE 3: Abuse by Political PARTY

\begin{tabular}{llllll}
\hline \hline Political Party & $\begin{array}{l}\text { No. Abusive } \\
\text { Tweets }\end{array}$ & Total No. Tweets & $\begin{array}{l}\text { \% of Tweets } \\
\text { Abusive }\end{array}$ & $\begin{array}{l}\text { No. of MPs in } \\
\text { sample }\end{array}$ & $\begin{array}{l}\text { Mean Abuse per } \\
\text { Party MP }\end{array}$ \\
\hline Lib Dems & 678 & 10,470 & 6.48 & 9 & 75.4 \\
UKIP & 75 & 2,559 & 2.93 & 1 & 75 \\
Conservative & 2,695 & 99,087 & 2.72 & 276 & 9.8 \\
Labour & 3,020 & 128,915 & 2.34 & 207 & 14.6 \\
Independent & 36 & 1,710 & 2.11 & 3 & 12 \\
DUP & 36 & 1,757 & 2.05 & 7 & 5.1 \\
SNP & 379 & 22,650 & 1.67 & 53 & 7.1 \\
Plaid Cymru & 6 & 514 & 1.17 & 3 & 2 \\
Green & 25 & 2,370 & 1.05 & 1 & 25 \\
SDLP & 2 & 284 & 0.70 & 3 & .67 \\
Sinn Fein & 0 & 342 & N/A & 4 & .0 \\
UUP & 0 & 59 & N/A & 2 & .0 \\
\hline Total & 6,952 & 270,717 & 2.57 & 569 & 12.2 \\
\hline \hline
\end{tabular}


Following this, it was found from the list of users who had sent abusive tweets to MPs, overall, are not serial transgressors. The 6,952 abusive messages sent to MPs was made by 4,775 Twitter users, which gives a mean of 1.4 abusive tweets per user in this list. This is somewhat low when contrasted with the whole dataset, whereby 270,717 tweets were sent by 83,648 different Twitter users (3.23 messages per user). Many abusers sent only one abusive message $(n=3,799)$, while only 28 accounts had sent over 10 abusive messages to MPs. This suggests that abuse is distributed across a vast number of different Twitter handles, and overall, is not perpetrated by a small group of highly abusive members. Accounts who had tweeted more than one abusive message tended to distribute their abusiveness across several MPs.

TABLE 4:

\begin{tabular}{ll}
\hline \hline $\begin{array}{ll}\text { Number of Abusive } \\
\text { Messages sent }\end{array}$ & $\begin{array}{l}\text { Frequency of } \\
\text { Accounts }\end{array}$ \\
\hline $1-10$ & 4,750 \\
$11-20$ & 17 \\
$21-30$ & 10 \\
$101-110$ & 1 \\
\cline { 2 - 2 } Total & 4,775 \\
\hline \hline
\end{tabular}

\section{DISCUSSION AND CONCLUSIONS}

The level of abuse, on first sight, appears relatively low. Indeed, given the general level of contempt for politicians amongst the electorate, we might have expected a greater volume of abuse. However, we used a relatively strict definition of abuse i.e. direct to an MP on one platform. We were not measuring abuse in general or abuse directed at family members or staff for example. Moreover, we have not assessed the totality of abuse across different technological platforms. Additionally, it is possible also that some abusive tweets were blocked or removed without being captured in our dataset. Since there is little or no previous comparable data, it is difficult to tell how far the problem of social media abuse is growing. James et al's study of selfreported abuse from 2010 is the only reference point we could find. If we use this as a base, then abuse on social media has certainly expanded significantly with many MPs now facing abuse of some sort on Twitter and a smaller number receiving more regular abuse. Again, though, how far this represents an overall growth in abuse is difficult to interpret since we don't know whether there is a substitution effect here i.e. whether, for example, abusers have moved from email or letter to Twitter.

Overall levels of abuse are only one part of the picture though. It is clear that certain individual politicians are targeted for abuse. This, not surprisingly, relates to their media profile generally and how active they are on Twitter. Gender and party seem to matter less here. However, our results do suggest that women MPs attract more hate speech and threatening behaviour. In part, this represents definitional issues around hate-speech but also reflects the different tone of abuse directed to some female MPs. Whilst not wishing to downplay the impact of abuse, it is worth noting that where abusive hate speech occurred, it often led to a significant show of support from other Twitter users. Nevertheless, even if the level is relatively low, it is still important to consider the perception and fear of abuse and whether this potentially restricts debate and the use of social media for connecting with the public. Some MPs have removed themselves from Twitter as a result of abuse and some self-censor before communicating on social media.

In terms of the pattern of abuse, our results confirm a more reactive model i.e. that Twitter abusers are often responding to something they have seen about the MP online or to the discussion of emotive political issues in which MPs have taken part. Abuse clearly relates to the nature and profile of political discussion. Hence, abuse peaked in our dataset with the parliamentary discussion of Brexit. Similarly, on a more regular basis we can also connect small 
spikes of abuse to the high profile weekly nature of PMQs. In general, there are some hints here of polarized nature of UK political debate on some issues, with several MPs being targeted especially for pro-remain views. Interestingly, there is also the appearance of terms of abuse (e.g. snowflake) spilling over from the recent highly polarized US presidential debate.

Although more work and research are required to identify abuser profiles and patterns of abuse, our initial findings do not necessarily fit the media stereotypes. The majority of abusers do not appear to be serial trolls tweeting late at night. Nor did we detect any networks of abusers although there was some minor evidence of bot activity. The character of most of the abuse was one-off comments in relation to political debates or events. Arguably, these are types of comments which would once have been privately shouted at a television screen - however, social media has given people more direct access to publicly shout such comments at those in the media spotlight. This potentially means that such abuse has more power and impact than past private communications, both specifically on the targets of abuse and on a more general perception of MPs. The apparently irregular nature of abusers also underlines a theoretical problem here. Whilst considerable attention has focused on trolling or cyber-bullying in both media discussion and social science literature, these are not necessarily helpful frames for understanding much of political abuse online. Most abuse was not from repeat abusers nor was it necessarily designed to amuse other tweeters or provoke response from the target as suggested by most definitions of trolling.

In sum, this study has attempted to provide an empirical benchmark for assessing abuse of politicians and to provide a methodology for doing so. We would argue that analysis of actual abuse online provides a more accurate and broader understanding than traditional self-reporting studies and, media representations of the problem. Nevertheless, there remains further work to be done: firstly, to compare different technological platforms to see whether the nature of platforms and the rules and norms around them can influence the civility of discussion. Secondly, we need larger, repeat studies to monitor whether social media abuse is growing and, if so, why. Thirdly, politics in the UK is often considered as one of the more adversarial political systems that potentially could encourage more aggressive forms of contact between politicians and citizens. Therefore, it would be useful to have comparative studies to help understand the influence of systemic factors (the nature of representative system, the party system, the linkage to constituency) to see whether patterns of abuse are replicated cross-nationally. 


\section{REFERENCES}

Adams, S.J., Hazelwood, T.E., Pitre, N.L., and Bedard, T.E. (2009). Harassment of Members of Parliament and the Legislative Assemblies in Canada by Individuals Believed to be Mentally Disordered. Journal of Forensic Psychiatry and Psychology, 20: 801-814.

Albrecht, S. (2006). Whose voice is heard in online deliberation? A study of participation and representation in political debates on the Internet. Information, Communication \& Society, 9, 62-82.

Barber, B. R. (1998). "Three Scenarios for the Future of Technology and Strong Democracy". Political Science Quarterly, 113: 573-589

Barbera, P. (2015). How Social Media Reduces Mass Political Polarization. Evidence from Germany, Spain, and the U.S. Paper prepared for APSA Conference.

Bartlett, J., Reffin, J., Rumball, N., and Williamson, S. (2014). Anti-Social Media. DEMOS: London. Available at: https://www.demos.co.uk/files/DEMOS_Anti-social_Media.pdf

BBC News (2017) 'Mistreatment of Women MPs Revealed', 25 January. http://www.bbc.co.uk/news/uk-politics-38736729.

Braun, V., and Clarke, V. (2006). Using Thematic Analysis in Psychology. Qualitative Research in Psychology, 3(2): 77-101.

Buckels, E.E., Trapnell, P.D., and Paulhus, D. (2014). Trolls just want to have fun. Personality and Individual Differences, 67: 97-102.

Buhrmester, M., Kwang, T., and Gosling, S.D. (2011). Amazon's Mechanical Turk: A new source of inexpensive, yet high-quality, data? Perspectives on Psychological Science, 6(1):3-5.

Burnap, P. and Williams, M.L. (2013). Cyber Hate Speech on Twitter: An Application of Machine Classification and Statistical Modelling for Policy and Decision Making. Policy \& Internet, 7(2): 223-242.

BuzzFeed News (2017a) 'The President Of Italy's Chamber Of Deputies Is Launching A Campaign Against Fake News', 8 February. https://www.buzzfeed.com/albertonardelli/the-president-of-italys-lower-house-says-fakenews-is-fuelli?utm_term=.qt3n6genl\#.jue 51oq5K.

BuzzFeed News (2017b) 'This is what the twitter abuse of politicians during the election really looked like'. 23 July, https://www.buzzfeed.com/tomphillips/twitter-abuse-of-mpsduring-the-election-doubled-after-the?utm_term $=. \operatorname{mvbQvVBxd\# .bdrW91dbA~}$

CBC News, (2016) 'Sandra Jansen latest in a long string of female politicians to face abuse'. 23 November.http://www.cbc.ca/news/canada/calgary/sandra-jansen-alberta-mlamisogyny-1.3865047.

Cha, M., Haddadi, H., Benevenuto, F. and Gummadi, K. (2010). "Measuring User Influence on Twitter: The Million Follower Fallacy". Paper presented to The Forth International AAAI Conference on Weblogs and Social Media, ICWSM 2010: May 23-26. Washington, DC. Available at: http://www.aaai.org/ocs/index.php/ICWSM/ICWSM10/paper/viewFile/1538/1826

Chen, W., Yuan, Y., and Zhang, L. (2010). Scalable influence maximization in Social Media Networks under the linear threshold model. Paper presented to 2010 IEEE International Conference on Data Mining: December 13-17. University of Technology Sydney, Australia. (pp. 88-97). Available at: http://ieeexplore.ieee.org/document/5693962/

Chikashi, N., Tetreault, J., Thomas, A., Mehdad, Y., \& Chang, Y. (2016). Abusive Language Detection in Online User Content. Paper presented at WWW 2016, April 11-15, 2016, Montreal, Quebec, Canada.

Chikashi, N., Tetreault, J., Thomas, A., Mehdad, Y., and Chang, Y. (2016). Abusive Language Detection in Online Content. Paper presented to $W W W$ 2016: April 11-15. Montreal, Canada.

Coleman, S. (1999). "Can the New Media Invigorate Democracy?” The Political Quarterly, 70: 1622.

Coleman, S. (2005). "New mediation and direct representation: reconceptualizing representation in the digital age", New Media \&o Society. 7.2: 177-198.

Colleoni, E., Rozza, A and Arvidsson, A. (2014). "Echo Chamber or Public Sphere? Predicting Political Orientation and Measuring Political Homophily in Twitter Using Big Data." Journal of Communication, 64 (2): 317-332. 
Daily Telegraph, (2016) 'Labour MP Jess Phillips receives more than 600 rape threats in one night'. 31 May. http://www.telegraph.co.uk/news/2016/05/31/labour-mp-receivesmore-than-600-rape-threats-in-one-night/.

Demos, (2016) The Use of Mysogynistic terms on Twitter. https://www.demos.co.uk/wpcontent/uploads/2016/05/Misogyny-online.pdf. (Last accessed 5 April 2017).

Dietz P, Martell DA (1989) Mentally Disordered Offenders in Pursuit of Celebrities and Politicians. Washington, DC: National Institute of Justice

Every-Palmer, S., Barry-Walsh, J., \& Pathé, M. (2015). Harassment, stalking, threats and attacks targeting New Zealand politicians: A mental health issue. Australian and New Zealand Journal of Psychiatry, 49, 634-641.

Farris, R., Ashar, A., Gasser, U., and Joo, D. (2016). Understanding Harmful Speech Online: Networked Policy Series. Cambridge, MA: Berkman Klein. Available at: https://papers.ssm.com/sol3/papers.cfm?abstract_id=2882824

Francoli, M. and Ward, S., (2008). '21st century soapboxes? MPs and their blogs'. Information Polity, 13(1-2): 21-39.

Gagliardone, I., Pohjonen, M., Beyene, Z., Zerai, A., Aynekulu, G., Bekalu, M., Bright, J., Moges, M.A., Seifu, M., Stremlau, N., Taflan, P., Gebrewolde, T.M., and Teferra, Z. (2016). Mechachal: Online Debates and Elections in Ethiopia - From Hate Speech to Engagement in Social Media. Available at: https://papers.ssrn.com/sol3/papers.cfm?abstract_id=2831369

Gazette, (2016) 'Corbyn row Twitter troll who threatened Labour MP is exposed - as a party member'. 1 July. http://www.gazettelive.co.uk/news/teesside-news/corbyn-row-twittertroll-who-11550844.

Guardian, (2016) 'David Lammy receives death threats after EU referendum result'. 4 July. https://www.theguardian.com/politics/2016/jul/04/david-lammy-receives-death-threatafter-eu-referendum-result.

Harp, D., \& Tremayne, M. (2006). The gendered blogosphere: Examining inequality using network and feminist theory. Journalism \& Mass Communication Quarterly, 83, 247-64.

Hermans, L. and Vergeer, M., (2013). 'Personalization in e-campaigning: A cross-national comparison of personalization strategies used on candidate websites of 17 countries in EP elections 2009'. New media \& society, 15 (1): 72-92.

Home Affairs Select Committee, (2017) Hate Crime and its violent consequences (HC609) http://data.parliament.uk/writtenevidence/committeeevidence.svc/evidencedocument/h ome-affairs-committee/hate-crime-and-its-violent-consequences/oral/49182.html.

Independent, (2016) 'Police investigation death threats targeting Remain-supporting Conservative MP Anna Soubry', 2 December. http://www.independent.co.uk/news/uk/politics/anna-soubry-jo-cox-murder-threatbrexit-eu-referendum-a $7452546 . h t m l$.

Inter Parliamentary Union (2016) Sexism, Harassment and Violence against Women Parliamentarians, Geneva: IPU

Jackson, N.A. (2003). MPs and web technologies: an untapped opportunity?. Journal of Public Affairs, 3 (2): 124-137.

Jackson, N.A. and Lilleker, D.G. (2009). MPs and E-representation: Me, MySpace and I. British Politics, 4(2): .236-264.

Jackson, N.A. and Lilleker, D. (2011). Microblogging, constituency service and impression management: UK MPs and the use of Twitter. The Journal of Legislative Studies, 17 (1): 86105.

James, D.V., Farnham, F.R., Sukhwal, S., Jones, K., Carlisle, J. and Henley, S., (2016). Aggressive/intrusive behaviours, harassment and stalking of members of the United Kingdom parliament: a prevalence study and cross-national comparison. The Journal of Forensic Psycbiatry \& Psychology, 27 (2): 177-197.

James, D.V., Mullen, P., Meloy, J.R., Pathe, M. Farnham, F., Preston, I., and Darnley, B. (2007). The Role of Mental Disorder in Attacks on European Politicians, 1990-2004. Acta Psychiatrica Scandinavica, 116(5): 334-344.

Jensen, J. L. (2003). Virtual democratic dialogue? Bringing together citizens and politicians. Information Polity, 8, 29-47. 
Joinson, A. (ed) (2007). Oxford Handbook of Internet Psychology. Oxford: OUP.

Journal.ie, (2016) We will kill you": Irish politicians speak out against online abuse. 19 June. Available at http:/ /www.thejournal.ie/irish-politicians-abuse-online-2833042-Jun2016/

Karvonen, L., (2010). The personalisation of politics: a study of parliamentary democracies. ECPR Press.

Laird, S. (2012). Instagram Users Share 10 Hurricane Sandy Photos Per Second. Mashable. Available at: http://mashable.com/2012/10/29/instagram-hurricane-sandy/

Lelkes, Y., Sood, G. and Iyengar, S. (2015), The Hostile Audience: The Effect of Access to Broadband Internet on Partisan Affect. American Journal of Political Science.

Lenhart, A., Ybarra, M., Zickuhr, K., and Prince-Freeney, M. (2016). Online Harassment, Digital Abuse, and Cyberstalking in America. New York, USA: Data \& Society. Available at: https://www.datasociety.net/pubs/oh/Online_Harassment_2016.pdf

Lilleker, D. and Jackson, N., (2014). 'Interacting and representing: can Web 2.0 enhance the roles of an MP?' ECPR Joint Sessions of Workshops, 14--19 March 2009, Lisbon.

Lumsden, K., and Morgan, H.M. (2017). Media Framing of Trolling and Online Abuse: Silencing Strategies, Symbolic Violence and Victim Blaming. Feminist Media Studies, 17(6).

McPherson, M., Smith-Lovin, L., and Cook, J.M. (2001). "Birds of a feather: Homophily in social networks". Annual Review of Sociology, 28: 415-444.

Murthy, D. (2017). The Ontology of Tweets: Mixed-Method Approaches to the Study of Twitter. In L. Sloan, and A. Quan-Haase. (eds). The Sage Handbook of Social Media Research Methods. London: Sage.

Mutz, D.C. and Martin, P.S. (2001). "Facilitating communication across lines of political difference: The role of mass media". American Political Science Review, 95 (1): 97-114.

Nobata, C., Tetreault, J., Thomas, A., Mehdad, Y., and Chang, Y. (2016). Abuse Language Detection in Online User Content. Proceedings of WWW'16 25th International Conference on World Wide Web. (pp.145-153).

Norris, P. (1999). Critical citizens: Global support for democratic government. OUP Oxford.

Papacharissi, Z. (2004). 'Democracy online: Civility, politeness, and the democratic potential of online political discussion groups'. New Media \& Society, 6 (2): 259-283.

Pathe $\square$, M., Phillips, J., Perdacher, E., \& Heffernan, E. (2014). The harassment of Queensland members of parliament: A mental health concern. Psychiatry, Psychology and Law, 21, 577584.

Prior, M. (2007). Post-broadcast democracy: How media choice increases inequality in political involvement and polarizes elections. Cambridge: Cambridge University Press

Prior, M. (2013). "Media and Political Polarisation". Annual Review of Political Science, 16: 101-27.

Ratkiewicz, J., Conover, M.D., Meiss, M., Goncalves, B., Flammini, A., and Menczer, F. (2011). Detecting and Tracking Political Abuse in Social Media. Paper presented to the $A A A I$ Conference on Weblogs and Social Media. Available at: http://www.aaai.org/ocs/index.php/ICWSM/ICWSM11/paper/view/2850

Rowe, I., (2015). 'Civility 2.0: a comparative analysis of incivility in online political discussion'. Information, Communication \& Society, 18(2): 121-138.

Schoeman-Morris, K.A., Scalora, M.J., Chang, G.H., Zimmerman, W.J., and Garner, Y. (2007). A Comparison of Email Versus Letter Threat Contacts towards Members of the United States Congress. Journal of Forensic Sciences, 52(5): 1142-1147.

Sellers, A.F. (2016). Defining Hate Speech. Cambridge, MA: Berkman Klein. Available at: https://papers.ssrn.com/sol3/papers.cfm?abstract_id=2882244

Serfaty, V., (2010). 'Web campaigns: Popular culture and politics in the US and French presidential elections'. Culture, Language, Representations, 8: 115-129.

Shane, P.M. (2004). Democracy Online: The Prospects For Political Renewal Through The Internet. Routledge: London.

Sloan, L., Morgan, J., Housley, W., Williams, M., Edwards, A., Burnap, P. and Rana, O. (2013). Knowing the Tweeters: Deriving sociologically relevant demographics from Twitter. Sociological Research Online, 18(3).

Sloan, L. (2017). Social Science 'Lite'? Deriving Demographic Proxies from Twitter. In L. Sloan, and A. Quan-Haase (eds). The Sage Handbook of Social Media Research Methods. London: Sage. 
Stromer-Galley, J. (2002). Diversity and political conversations on the Internet: Users' perspectives. Journal of Computer-Mediated Communication, 8. http:/jcmc.indiana.edu/ vol8/issue 3/stromergalley.html.

Suler, J. (2004). 'The online disinhibition effect.' Cyberpsychology \& behavior, 7 (3): 321-326.

Sunstein, C.R. (2009). Republic 2.0. Princeton, NJ: Princeton University Press.

Thelwall, M., Buckley, K., and Paltoglou, G. (2012). Sentiment Strength detection for the social web. Journal of the American Society for Information Science and Technology, 63(1):163-173.

Theocharis, Y., Barberá, P., Fazekas, Z., Popa, S.A. and Parnet, O., (2016). 'A Bad Workman Blames His Tweets: The Consequences of Citizens' Uncivil Twitter Use When Interacting With Party Candidates'. Journal of Communication, 66 (6): 1007-1031.

Trammell, K.D., \& Keshelashvili, A. (2005). Examining the new influencers: A self- presentation study of A-list blogs. Journalism \& Mass Communication Quarterly, 82, 968-82.

Voss, A., Lvov, I., and Thompson, S.D. (2017). Data Storage, Curation and Preservation. In L. Sloan, and A. Quan-Haase (eds). The Sage Handbook of Social Media Research Methods. London: Sage.

Ward, S. and Lusoli, W. (2005). 'From weird to wired': MPs, the Internet and representative politics in the UK'. Journal of Legislative Studies, 11(1): 57-81.

Williamson, A. (2009). 'The effect of digital media on MPs' communication with constituents'. Parliamentary Affairs, 62 (3): 514-527.

\section{APPENDIX 1:}

IDENTIFIERS OF ABUSIVE/HATE-SPEECH TwEETS TO MPS

These are the keywords used as described within the methodology to identify abusive or hate filled messages towards MPs. Deviations of these keywords were also used. For example, "fuck off” would also identify tweets which included "fuckoff" and "fuck-off'. Plurals of words were also collected.

\begin{tabular}{llll}
\hline \hline 'and die' & Faggot & Muzzies & Snowflake \\
Arsehole & Fascist & Nazi & Swamp \\
Bastard & Fool & Nonce & Thug \\
Bigot & Fuck off & Nutjob & Tosser \\
Bitch & Fuck You & Pedo/paedophile & Traitor \\
Buffoon & Fuckin/fucking & Pervert & Troll \\
Bullshit & Golliwog & Pillock & Turd \\
Cock-nosed & Hypocritical & Piss off & Twat \\
Cow & Ideologue & Ponce & Undemocratic \\
Crony & Idiot & Prick & Vile \\
Cunt & Imbecile & Radical & Wanker \\
Dick head & Kike & Rag Head & Wankstain \\
"Die in" & Kuffar & Rape & Weasle \\
Dirty & Libtard & Redtory & WhiteGenocide \\
Disgrace & Londonistan & Retard & Whore \\
Dishonourable & Loon & Scum & Wretch \\
Dumb & Loser & Shill & "You Racist" \\
Dyke & Lunatic & Shit & Zealot \\
Elitist & Moron & Slag & \\
Extremist & Murat/Muzrat & Sleaze & \\
\hline \hline
\end{tabular}

